\title{
Cardiac parameters and endothelial function in a strength athlete: a case report
}

\author{
Guilherme B. Grezzana ${ }^{1}$, David W. Moraes ${ }^{1}$, Diego V. Silva ${ }^{1}$, Bruna Eibel ${ }^{1}$, Maximiliano I. Schaun ${ }^{1}$, \\ Alexandre M. Lehnen ${ }^{1,2}$ \\ ${ }^{I}$ Fundação Universitária de Cardiologia, Instituto de Cardiologia do Rio Grande do Sul, Porto Alegre, RS, Brazil; \\ ${ }^{2}$ Faculdade Sogipa de Educação Física, Porto Alegre, RS, Brazil
}

\begin{abstract}
Aims: We aimed to discuss a case of strength training athlete who competes in international competitions regarding cardiac (dimension and function), vascular (endothelium and vascular resistance), hemodynamic (blood pressure), given limited evidence supporting these cardiovascular adaptations as well as concerning endothelial function in long-term high-intensity strength training. Methods: We assessed heart structure and function (echocardiography); systolic (SBP) and diastolic blood pressure (DBP); endothelium-dependent vasodilation (flow-mediated dilation, FMD); maximum force tested in the squat, bench press, and deadlift; and maximum oxygen consumption (spirometry). Results: powerlifter's cardiac dimensions (interventricular septum $13 \mathrm{~mm}$; posterior wall thickness $12 \mathrm{~mm}$; LV diastolic diameter $57 \mathrm{~mm}$; left ventricle mass $383 \mathrm{~g}$; LV mass adjusted by body surface area $151.4 \mathrm{~g} / \mathrm{m}^{2}$ ) are above the proposed cutoff values beyond which pathology may be considered. Moreover, cardiovascular function systolic (ejection fraction by Simpson's rule, 71\%) is preserved and FMD measure is fairly close and above normal; however, a mild increase in systolic and diastolic blood pressure was observed (130/89 mmHg, respectively). Conclusion: Cardiac remodeling cannot be viewed as either pathological or harmful to the cardiovascular system. Furthermore, we showed an improvement in endothelial function.
\end{abstract}

Keywords: athlete's heart, ventricular hypertrophy, flow-mediated dilation, strength training.

\section{Introduction}

The heart develops anatomical and physiological adaptive changes in response to exercise training, particularly long-term aerobic exercise, that constitute a clinical entity classically called "athlete's heart". Another question regarding cardiovascular changes in response to exercise training is about the existence of an "athlete artery". Studies have shown that peripheral and coronary arteries of athletes are larger than those of control subjects, and peak blood flow to the legs is enhanced in athletes suggests that resistance arteries undergo increases in their crosssectional area. Such cardiovascular remodeling phenomenon could be a result of hemodynamic shear stress mediated by endothelial factors ${ }^{2}$.

In contrast, researchers have investigated a potentially negative association between high-intensity strength training and cardiovascular health ${ }^{3}$, since it involves a great amount of slow-speed contractions using high loads close to the maximum, increasing peripheral vascular resistance (PVR), left ventricle (LV) pressure overload. Cardiovascular remodeling in response to high-intensity strength training could induce changes over time (concentric LV hypertrophy) that are similar to those seen in serious heart conditions such as hypertrophic cardiomyopathy ${ }^{4}$ or hypertensive disease. However, this state has not been evidenced in strength training athletes ${ }^{5,6}$ and some findings may be misinterpreted and lead to an incorrect diagnosis (false positive). Thus, in current clinical practice, a special attention should be given to "a misdiagnosed condition can ensure an unnecessary cessation of an exercise program"'. This problem goes beyond "high-performance" and also affects amateur athletes.

Due to the complexity of the research question, mainly in the difficulty of recruiting the sample with the same characteristics including do not use anabolic steroid, common among powerlifters, we presented a case study to discuss cutoff parameters structural and functional cardiac changes, blood pressure and endothelium-dependent vasodilation in a powerlifter.

\section{Case report}

RC, 35-year-old male, height $1.84 \mathrm{~m}$, and weight $135 \mathrm{~kg}$. The powerlifter, who competes in international competitions (including The World's Strongest Man - US). Fifteen years of powerlifting training (5 days/week; 60 minutes/day) without aerobic exercises. No prior history of cardiovascular conditions. Denies the use of anabolic steroids or any other drugs for the last 24 months. We performed a strength assessment for the following exercises: squat $390 \mathrm{~kg}$; bench press $270 \mathrm{~kg}$; deadlift 415 $\mathrm{kg}$, and total load $1,075 \mathrm{~kg}$. We conducted an echocardiographic assessment on a different day (all images were stored and sent to a second echocardiography specialist for blind evaluation of images) - Figure 1. The cutoff values for the parameters assessed are presented by specific studies with athletes according to the Recommendations for Chamber Quantification by Lang (2005) (from the American Society in conjunction with the European Association of Echocardiography) and Brazilian Guidelines of Echocardiography Indications: LV ejection fraction (LVEF) (Simpson's method) 71\%; preserved diastolic function; aorta 29 
$\mathrm{mm}$; left atrium $38 \mathrm{~mm}$; interventricular septum $13 \mathrm{~mm}$ [cutoff values by Whyte (2004) and Lang (2005): 12-13 mm]; posterior wall thickness $12 \mathrm{~mm}$ [cutoff values by Lang (2005): $11 \mathrm{~mm}$ ]; LV diastolic diameter $57 \mathrm{~mm}$ [cutoff values by Lang (2005): 59 $\mathrm{mm}$ ]; LV mass $383.0 \mathrm{~g}$ [cutoff values by Lang (2005): $225.0 \mathrm{~g}$ ] and LV mass adjusted by body surface area (BSA) $151.4 \mathrm{~g} / \mathrm{m}^{2}$ [cutoff values by Lang (2005): $115 \mathrm{~g} / \mathrm{m}^{2}$ ]; and interventricular septum-posterior ventricular wall thickness ratio 1.08 [cutoff value by Caselli (2008): 1.03]. We calculated the relative wall thickness (RWT) by the formula RWT $=(2 \times$ posterior wall thickness) / LV diastolic diameter and found a RWT of 0.42. Thus, the athlete showed increased LV mass index and an inaccurate diagnosis of concentric hypertrophy (Figure 2) according to the Recommendations for Chamber Quantification ${ }^{7}$ and Brazilian Guidelines of Echocardiography Indications ${ }^{8}$. RC also showed 130/89 mmHg (systolic/diastolic blood pressure; duplicate measurements) and $\mathrm{VO}_{2} \max$ (by spirometry) of $25.1 \mathrm{~mL} \mathrm{O}_{2} /$ $\mathrm{kg} \cdot \mathrm{min}^{-1}$. Finally, vascular measurements showed flow-mediated dilation (FMD, according to the literature ${ }^{11}$, non-blinded evaluation) of $9.64 \%$, and PVR of $8.00 \mathrm{mmHg} / \mathrm{cm}^{-1}$.

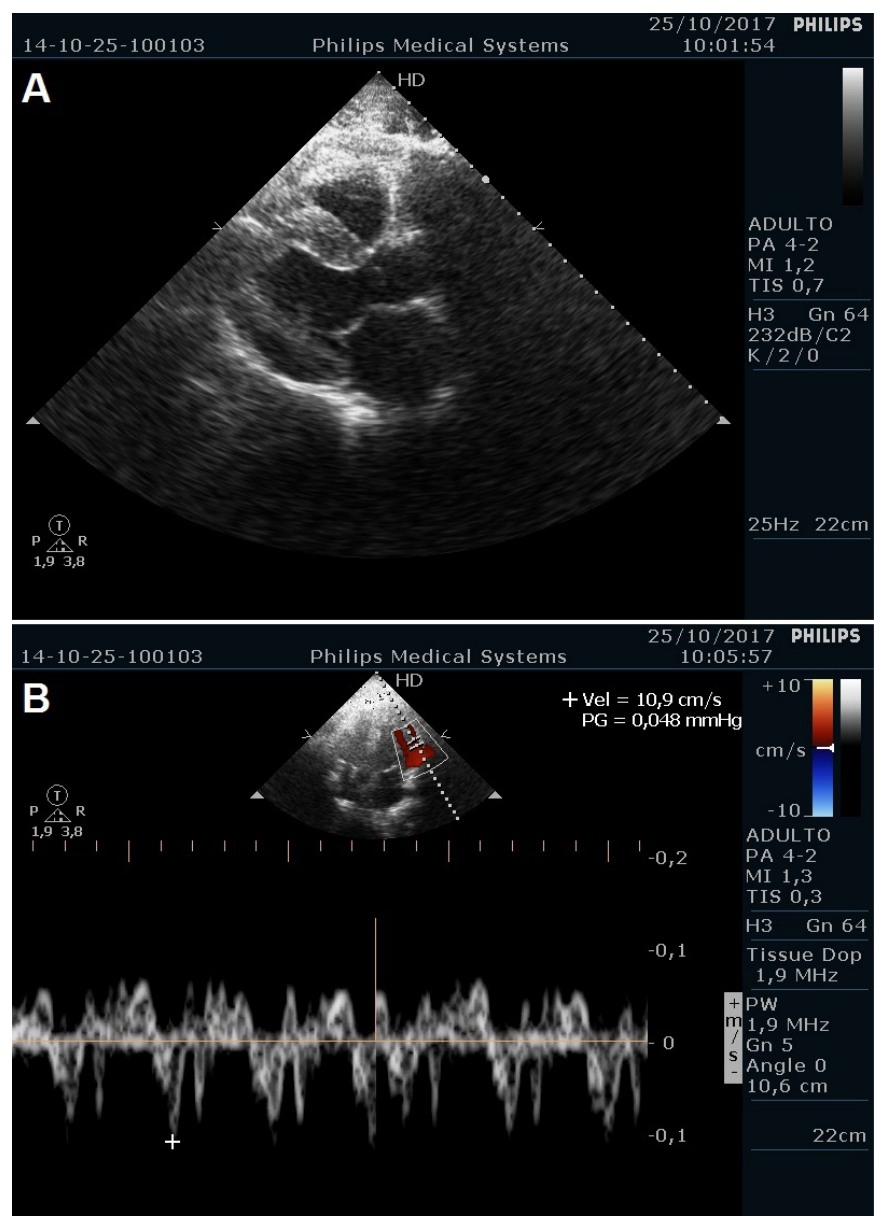

Figure 1. Echocardiographic imaging of case (powerlifter). Panel A: two-dimensional imaging using a parasternal longitudinal view. Panel B: four-chamber view on tissue Doppler for assessment of left ventricle diastolic function.

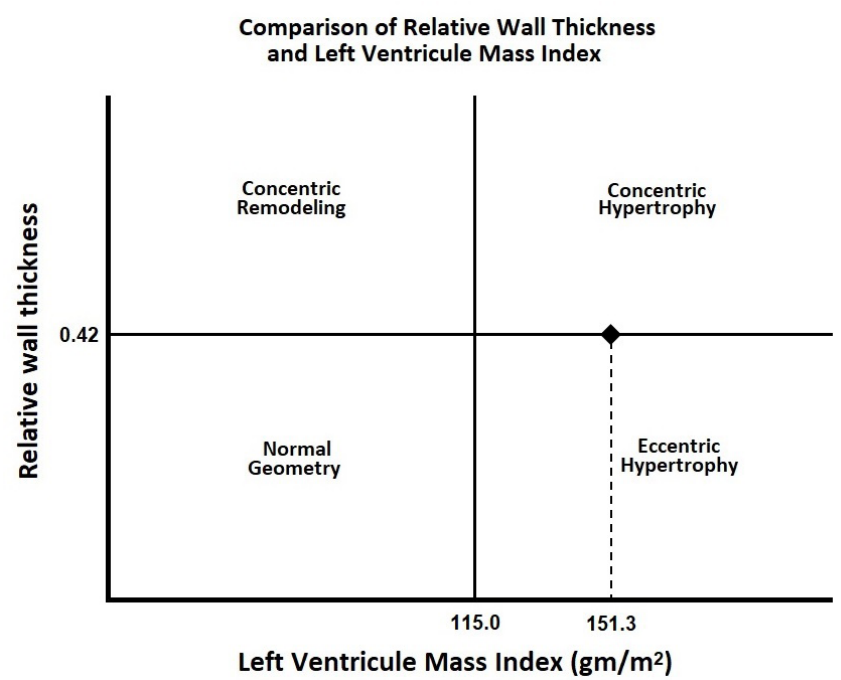

Figure 2. Relationship between relative wall thickness and left ventricle mass indexed by body surface area. The comparison permits categorization of an increase in LV mass as either concentric (relative wall thickness $>=0.42$ ) or eccentric (relative wall thickness $<0.42$ ) hypertrophy, according to Lang (2005) and Camarozano (2009). Our athlete (RC) is placed with 0.42 (relative wall thickness) and $151.5 \mathrm{gm} / \mathrm{m} 2$ (left ventricle mass index).

The case report was conducted in accordance with the Ethical Principles of the Declaration of Helsinki and approved by the Research Ethics Committee at Instituto de Cardiologia do RS/ Fundação Universitária de Cardiologia (ICFUC) (protocol \#417.492).

\section{Discussion}

Interestingly, the powerlifter's cardiac dimensions are above the proposed cutoff values and could be considered a pathological state. However, RC showed that cardiovascular function is preserved. The literature has reported that both high-intensity aerobic and strength athletes exhibit increased LV parameters compared with physically inactive subjects? Echocardiographic assessment based on BSA must be performed to compare individuals of different body size. A 2013 meta-analysis reported that all structural LV parameters were greater in aerobic training (AT) and strength training (ST) athletes than sedentary subjects (S) including LV mass (AT: 232, ST: 220 and S: $166 \mathrm{~g}$ ), interventricular septum thickness (AT: 11.0, ST: 11.0 and S: $9.2 \mathrm{~mm}$ ) and LV end-diastolic diameter (AT: 54.8, ST: 52.4 and S: $50.1 \mathrm{~mm})^{12}$. Based on Utomi et al. ${ }^{12}$ proposed cutoff criteria, we found increased LV mass, intraventricular septum thickness, and LV end-diastolic diameter in the powerlifter. In contrast, LV mass, interventricular septum and LV end-diastolic diameter measures were below the upper normal cutoff values in the long-distance runner. Using a different approach, the multicenter Normal 
Reference Ranges for Echocardiography (NORRE) Study has proposed the following normal cutoff values for echocardiographic measurements in males: LV mass 145.6 \pm 36.7 $\mathrm{g}$, interventricular septum thickness $9.2 \pm 1.6 \mathrm{~mm}$, posterior ventricular wall thickness $9.3 \pm 1.5 \mathrm{~mm}$ and LV end-diastolic diameter $46.2 \pm 4.8 \mathrm{~mm}^{13}$. If we apply these criteria to our case, all cardiovascular parameters studied are increased for the powerlifter case. The finding of ventricular wall thickness in this case does not offer solid evidence to support the hypothesis of concentric hypertrophy in strength athletes ${ }^{12}$. Other factors should be evaluated, in particular, RWT and LV mass adjusted by BSA (Figure 2) 7,8,14. Furthermore, preserved systolic and diastolic functions seen in the athlete, possibly, have more important implications than cardiac dimensions ${ }^{13}$.

Cardiac adaptive changes in long-distance runners, contradictory to the commonly accepted knowledge, seem to be biphasic: concentric hypertrophy developed first and then eccentric hypertrophy developed later ${ }^{15}$. Contradictorily, in our case study, strength training with predominantly isometric exercises would lead to increased ventricular wall thickness with no increase in chamber volume resulting from pressure overload (increased afterload) rather than volume overload due to increased blood pressure, as seen in our athlete.

Despite the above-mentioned differences in cardiac remodeling, FMD measure is fairly close and above normal ${ }^{11}$ ( $8 \%$ for Correti's Studies). Blood flow redistribution could in part explain similar FMD measure found in our case. It is an interesting finding given that the exercise training modality studied has quite different biomechanical when compared with aerobic exercises that knowingly improves endothelial function through increased blood flow and enhanced shear stress during exercise. A likely explanation for increased FMD values in our case is the mechanical compression of resistance blood vessels during weightlifting, followed by an abrupt release of blood flow thus producing shear stress as well ${ }^{2}$.

\section{Conclusion}

Studies have shown little supportive evidence of the association of concentric hypertrophy with strength exercise, and apparently, this feature may have been misinterpreted because of assumptions based on anatomical criteria only (cardiac dimensions). Our case shows that cardiac remodeling is specific to the training modality and cannot be viewed as either pathological or harmful to the cardiovascular system. Although it is difficult to research, this subject is relevant, and it must be explored at several angles to increase the evidence of misleading clinical diagnoses.

\section{Acknowledgment}

The authors thank Carla Finger for her review of the English language.

\section{References}

1. Pluim BM, Zwinderman AH, van der Laarse A, van der Wall EE. The athlete's heart. A meta-analysis of cardiac structure and function. Circulation. 2000;101(3):336-44.

2. Tinken TM, Thijssen DH, Hopkins N, Dawson EA, Cable NT, Green DJ. Shear stress mediates endothelial adaptations to exercise training in humans. Hypertension. 2010;55(2):312-8. DOI: 10.1161/ HYPERTENSIONAHA.109.146282.

3. Umpierre D, Stein R. Hemodynamic and vascular effects of resistance training: implications for cardiovascular disease. Arq Bras Cardiol. 2007;89(4):256-62.

4. Dores H, Freitas A, Malhotra A, Mendes M, Sharma S. The hearts of competitive athletes: an up-to-date overview of exercise-induced cardiac adaptations. Revista portuguesa de cardiologia : orgao oficial da Sociedade Portuguesa de Cardiologia $=$ Portuguese journal of cardiology : an official journal of the Portuguese Society of Cardiology. 2015;34(1):51-64. DOI: 10.1016/j.repc.2014.07.010.

5. McCann GP, Muir DF, Hillis WS. Athletic left ventricular hypertrophy: long-term studies are required. Eur Heart J. 2000;21(5):351-3. DOI: 10.1053/euhj.1999.1783.

6. Haykowsky MJ, Dressendorfer R, Taylor D, Mandic S, Humen D. Resistance training and cardiac hypertrophy: unravelling the training effect. Sports Med. 2002;32(13):837-49.

7. Lang RM, Bierig M, Devereux RB, Flachskampf FA, Foster E, Pellikka PA et al. Recommendations for chamber quantification: a report from the American Society of why's Guidelines and Standards Committee and the Chamber Quantification Writing Group, developed in conjunction with the European Association of Echocardiography, a branch of the European Society of Cardiology. J Am Soc of Echocardiogr : official publication of the American Society of Echocardiography. 2005;18(12):1440-63. DOI: 10.1016/j.echo.2005.10.005.

8. Camarozano A, Rabischoffsky A, Maciel B, Brindeiro Filho D, Horowitz E, Pena J et al. Sociedade Brasileira de Cardiologia. Diretrizes das Indicações da Ecocardiografia. Arq Bras Cardiol. 2009;93(6 supl.3):e265-e302.

9. Whyte GP, George K, Sharma S, Firoozi S, Stephens N, Senior R et al. The upper limit of physiological cardiac hypertrophy in elite male and female athletes: the British experience. Eur J Appl Physiol. 2004;92(4-5):592-7. DOI: 10.1007/s00421-004-1052-2.

10. Caselli S, Pelliccia A, Maron M, Santini D, Puccio D, Marcantonio A et al. Differentiation of hypertrophic cardiomyopathy from other forms of left ventricular hypertrophy by means of three-dimensional echocardiography. Am J Cardiol. 2008;102(5):616-20. DOI: 10.1016/j.amjcard.2008.04.033.

11. Corretti MC, Anderson TJ, Benjamin EJ, Celermajer D, Charbonneau F, Creager MA et al. Guidelines for the ultrasound assessment of endothelial-dependent flowmediated vasodilation of the brachial artery: a report of 
the International Brachial Artery Reactivity Task Force. J Am Coll Cardiol. 2002;39(2):257-65.

12. Utomi V, Oxborough D, Whyte GP, Somauroo J, Sharma $\mathrm{S}$, Shave R et al. Systematic review and meta-analysis of training mode, imaging modality and body size influences on the morphology and function of the male athlete's heart. Heart. 2013;99(23):1727-33. DOI: 10.1136/ heartjnl-2012-303465.

13. Kou S, Caballero L, Dulgheru R, Voilliot D, De Sousa C, Kacharava $\mathrm{G}$ et al. Echocardiographic reference ranges for normal cardiac chamber size: results from the NORRE study. Eur Heart J Cardiovasc Imaging. 2014;15(6):680-90. DOI: $10.1093 /$ ehjci/jet284.

14. Ferreira Filho P. Padrões de Hipertrofia e Geometria do Ventrículo Esquerdo pela Ecocardiografia Transtorácica. Rev bras ecocardiogr imagem cardiovasc. 2012;25(2):103-15.

15. Arbab-Zadeh A, Perhonen M, Howden E, Peshock RM, Zhang R, Adams-Huet B et al. Cardiac remodeling in response to 1 year of intensive endurance training.
Circulation. 2014;130(24):2152-61. DOI: 10.1161/ CIRCULATIONAHA.114.010775.

\section{Corresponding author}

Dr Alexandre Machado Lehnen Instituto de Cardiologia do Rio Grande do Sul. Av. Princesa Isabel, 395. Bairro Santana, Porto Alegre, RS, Brazil Email: amlehnen@gmail.com

Manuscrip received on March 14, 2018

Manuscrip accepted on June 20, 2018

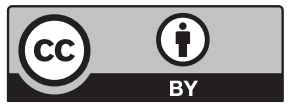

Motriz. The Journal of Physical Education. UNESP. Rio Claro, SP, Brazil - eISSN: 1980-6574 - under a license Creative Commons - Version 3.0 